\title{
Diferentes doses e épocas de aplicação de zinco na cultura da soja
}

\author{
Fernando Castro de Oliveira ${ }^{1}$, Cleiton Gredson Sabin Benett ${ }^{1}$, Katiane Santiago Silva Benett ${ }^{1}$, \\ Luciana Maria da Silva ${ }^{1}$, Bruna do Carmo Vieira ${ }^{2}$ \\ ${ }^{1}$ Universidade Estadual de Goiás, Campus Ipameri, Ipameri-GO, Brasil. E-mail: castrodeoliveira.10@gmail.com, \\ cleiton.benett@gmail.com, katiane.benett@gmail.com, luy.mari@hotmail.com \\ ${ }^{2}$ Instituto Federal Goiano, Campus Urutaí, Urutaí-GO, Brasil. E-mail: bruna03_@ hotmail.com
}

Recebido: 28/10/2017; Aceito: 01/11/2017.

\section{RESUMO}

A soja é uma das culturas mais importantes do mundo sendo sua produtividade afetada pela deficiência do micronutriente zinco. O presente trabalho teve como objetivo avaliar o efeito de doses e épocas de aplicação de zinco nas características agronômicas da soja, cultivada em solo da região do Cerrado. O delineamento experimental utilizado foi o de blocos casualizados em esquema fatorial $2 \times 5$, sendo, duas épocas de aplicação (estádio V9 e R1) e cinco doses (0, 3, 6, 9 e $12 \mathrm{~kg} \mathrm{ha}^{-1}$ de zinco), com quatro repetições. Avaliou-se teor de zinco foliar, teor relativo de clorofila, altura de planta, diâmetro do caule, altura de inserção da primeira vagem, número de vagens por planta, número de grãos por vagem, número de nós reprodutivos por planta, massa de 100 grãos e produtividade de grãos. A adubação com $\mathrm{Zn}$ influenciou positivamente o teor foliar de $\mathrm{Zn}$, altura de plantas, diâmetro do caule, altura de inserção da primeira vagem, número de vagens por planta, número de nós reprodutivos por planta, massa de 100 grãos e produtividade de grãos. A massa de 100 grãos e a produtividade de grãos apresentaram diferença significativa entre as épocas de aplicação, com resultados superiores para as médias de V9. De acordo com estes resultados recomenda-se a adubação com Zn na cultura da soja.

Palavras-chave: Glycine max (L.), adubação, micronutrientes, produção.

\section{Different doses and application times of zinc in soybean crop}

\begin{abstract}
Soybean is one of the most important crops in the world and its productivity is affected by zinc micronutrient deficiency. The present work had the objective of evaluating the effect of doses and application times of zinc on the agronomic characteristics of soybean cultivated in soil of the Cerrado region. The experimental design was a randomized complete block design in a 2 x 5 factorial design, with two application times (V9 and R1 stages) and five doses $\left(0,3,6,9\right.$ and $12 \mathrm{~kg} \mathrm{ha}^{-1}$ of zinc), with four replicates. Leaf zinc content, relative chlorophyll content, plant height, stem diameter, height of first pod insertion, number of pods per plant, number of grains per pod, number of reproductive nodes per plant, mass of 100 grains and grain yield were measured. Fertilization with $\mathrm{Zn}$ positively influenced $\mathrm{Zn}$ leaf content, plant height, stem diameter, height of first pod insertion, number of pods per plant, number of reproductive nodes per plant, mass of 100 grains and grain yield. The mass of 100 grains and the yield of grains presented significant difference between the application times, with superior results for the means of V9. According to these results fertilizations with $\mathrm{Zn}$ in the soybean crop is recommended.
\end{abstract}

Key words: Glycine Max (L.), fertilization, micronutrients, production. 


\section{Introdução}

A soja [Glycine $\max$ (L.) Merrill.] é uma das culturas mais importantes do mundo, sendo utilizada, principalmente, como fonte de alimentos para humanos e animais. Sua importância econômica vem crescendo mundialmente devido à grande demanda da China por essa oleaginosa. Além de ser uma importante fonte de alimento, os grãos de soja têm sido cada vez mais utilizados pela indústria química, farmacêutica e também pela agroindústria, na produção de farelo e óleo (FREITAS, 2011).

Com a crescente demanda mundial por alimentos e o potencial de expansão das áreas agrícolas chegando ao limite, é necessário o investimento em tecnologias de produção que proporcionem aumento de produtividade das áreas agrícolas já exploradas. Para que ocorra incremento da produtividade de soja no Brasil, é de fundamental importância o avanço científico e tecnológico em relação ao conhecimento das exigências nutricionais dessa cultura (GONÇALVES JÚNIOR et al., 2010).

Os solos do Cerrado possuem baixa disponibilidade de $\mathrm{Zn}$ e embora este micronutriente seja exigido pelas plantas em menores quantidades, há necessidade de boa disponibilidade para o adequado desenvolvimento das plantas, o que despertou interesse dos agricultores e técnicos (RESENDE, 2004). Ao lado do boro (B), o zinco $(\mathrm{Zn})$ é o micronutriente que mais frequentemente promove deficiência nas culturas, nos solos das regiões tropicais (FAQUIN, 2005), sendo que, de maneira geral, os solos brasileiros apresentam teores insuficientes de $\mathrm{Zn}$, havendo a necessidade de adicioná-lo aos sistemas de cultivo (VENDRAME et al., 2007). Porém, a aplicação dos nutrientes deve ser feita de forma equilibrada protegendo as culturas contra os antagonismos que possam vir a ocorrer na nutrição mineral das plantas, como resultado de relações não balanceadas dos nutrientes no solo e nas plantas (SOUZA et al., 2010).

O Zn é um dos micronutrientes mais importantes para as plantas, pois participa em diversos processos como: fotossíntese, respiração, controle hormonal, síntese de aminoácidos e de proteínas, redução do nitrato e desintoxicação de radicais livres (MARSCHNER, 2012). Dessa forma, sua deficiência causa encurtamento dos internódios, com produção de folhas pequenas, cloróticas e lanceoladas, e as folhas mais novas ficam com clorose internerval de coloração amarelo-ouro e as nervuras com cor verde escura (SFREDO, 2008).

A soja é classificada como cultura de média capacidade de resposta ao $\mathrm{Zn}$ (MALAVOLTA; KLIEMANN, 1985). Além disso, a acumulação deste micronutriente na soja é lenta nos primeiros 30 dias após semeadura, sendo que sua máxima acumulação é observada aos 60 - 90 dias, o que pode acarretar diferentes respostas da cultura quando o $\mathrm{Zn}$ for aplicado em diferentes épocas de desenvolvimento (BATAGLIA; MASCARENHAS, 1977).

Alguns autores observaram resposta na produção de soja após adubação com Zn. Garcia et al. (2009) verificaram que tanto o tratamento de sementes, quanto a aplicação foliar com cobre e zinco proporcionaram melhor desenvolvimento e maior produtividade da soja. Inocêncio et al. (2012) também verificaram aumento na produtividade da soja quando se realizou fertilização com $\mathrm{Zn}$, mesmo em solo com teor do micronutriente acima do nível crítico. Porém, trabalhos de pesquisa envolvendo adubação com $\mathrm{Zn}$ na cultura da soja na região do Cerrado ainda são, relativamente, poucos, havendo assim, a necessidade de se realizar pesquisas sobre esse tema.

O presente trabalho teve como objetivo avaliar o efeito de doses e épocas de aplicação de zinco nas características agronômicas da soja, cultivada em solo da região do Cerrado.

\section{Material e Métodos}

O experimento foi conduzido em campo na safra 2014/15, na área experimental da Universidade Estadual de Goiás, Câmpus de Ipameri, localizada no município de Ipameri-GO com $17^{\circ} 43^{\prime}$ de latitude sul e $48^{\circ} 22^{\prime}$ de longitude oeste e altitude média de $800 \mathrm{~m}$.

O clima da região, segundo a classificação de Köppen é definindo como tropical úmido (AW), com temperaturas elevadas, chuvas no verão e seca no inverno, apresentando temperatura máxima média anual de $30,6^{\circ} \mathrm{C}$ e temperatura mínima média anual de $18,3^{\circ} \mathrm{C}$, precipitação média anual de $1.334 \mathrm{~mm}$ e umidade relativa média anual de 65,8\% (INMET, 2016). As temperaturas mínimas e máximas e a precipitação total de cada mês no período em que foi conduzido o experimento são mostradas na Figura 1.

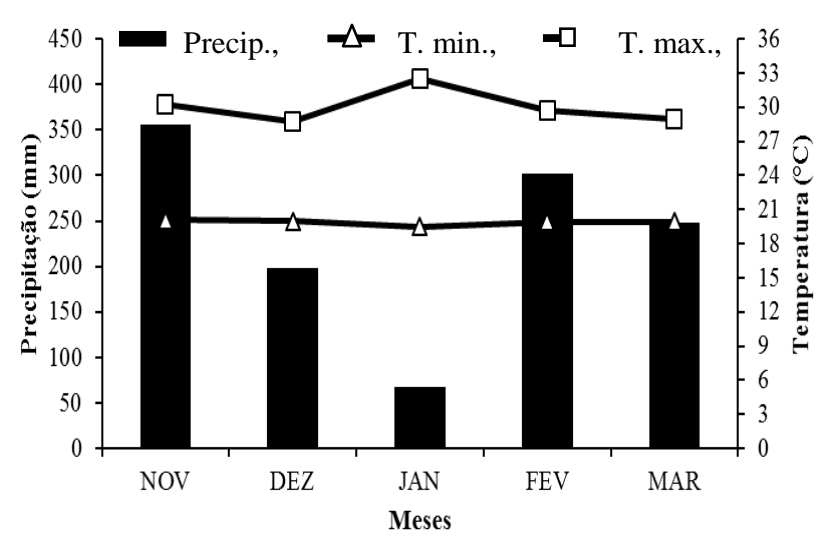

Figura 1. Variações da precipitação (Precip., mm), temperatura máxima média (T. max., ${ }^{\circ} \mathrm{C}$ ) e temperatura mínima média (T. min., ${ }^{\circ} \mathrm{C}$ ), médias mensais na região de Ipameri - GO. Ipamerí - GO, 2014/15. Fonte: Inmet, 2016. 
O solo da área experimental classificado como Latossolo Vermelho-Amarelo distrófico com textura argilosa (SANTOS et al., 2013) continha o seguintes atributos químicos e físicos determinados antes da instalação do experimento, segundo metodologia proposta por Ribeiro et al. (1999); atributos químicos: na camada 6,4 $\mathrm{mg} \mathrm{dm}^{-3}$ de $\mathrm{P}$ (Mehlich 1); $20 \mathrm{mg} \mathrm{dm}^{-3} \mathrm{de}$ M. O.; 4,7 de pH $\left(\mathrm{CaCl}_{2}\right) ; 0,25 ; 1,0 ; 0,4$ e 3,5 $\mathrm{cmol}_{\mathrm{c}} \mathrm{dm}^{-}$ ${ }^{3}$ de $\mathrm{K}, \mathrm{Ca}, \mathrm{Mg}$ e $\mathrm{H}+\mathrm{Al}$ respectivamente; $0,8 \mathrm{mg} \mathrm{dm}^{-3} \mathrm{de}$ $\mathrm{Zn}$ e $32 \%$ de saturação por bases; atributos físicos da granulometria: 475,75 e $450 \mathrm{~g} \mathrm{dm}^{-3}$ de argila, silte e areia, respectivamente.

O delineamento experimental utilizado foi o de blocos casualizados, com 10 tratamentos e quatro repetições, arranjados em esquema fatorial 2 x 5 , sendo duas épocas de aplicação: estádio V9 (oitava folha trifoliolada completamente desenvolvida) e R1 (início do florescimento) e cinco doses $\left(0,3,6,9\right.$ e $12 \mathrm{~kg} \mathrm{ha}^{-1}$ de zinco), sendo o sulfato de zinco a fonte utilizada (20\% de $\mathrm{Zn}$ ), aplicado via solo.

A semeadura foi realizada no dia 20 de novembro de 2014 utilizando uma semeadora para plantio direto com oito linhas e espaçamento entre linhas de $0,45 \mathrm{~m}$. A adubação de base foi realizada simultaneamente à semeadura aplicando-se a quantidade indicada na análise de solo, sendo aplicados $350 \mathrm{~kg} \mathrm{ha}^{-1}$ da fórmula 02-20-18, equivalente à aplicação de $7 \mathrm{~kg} \mathrm{ha}^{-1}$ de $\mathrm{N}, 70$ $\mathrm{kg} \mathrm{ha}^{-1}$ de $\mathrm{P}_{2} \mathrm{O}_{5}$ e $63 \mathrm{~kg} \mathrm{ha}^{-1}$ de $\mathrm{K}_{2} \mathrm{O}$.

A cultivar utilizada foi a M7739 IPRO com uma população aproximada de 290 mil plantas por hectare. As sementes foram tratadas com inseticida, fungicida e inoculante de rizóbio. Nos estádios V9 e R1 foram aplicadas as doses de $\mathrm{Zn}$ referentes aos respectivos tratamentos. O adubo foi aplicado em superfície e distribuído a uma distância de $0,1 \mathrm{~m}$ da linha da cultura. O controle de pragas, doenças e plantas daninhas foi realizado quando necessário de acordo com as Tecnologias de Produção de Soja (EMBRAPA, 2013). As parcelas experimentais foram constituídas de seis linhas com espaçamento de $0,45 \mathrm{~m}$ entre linhas e $5 \mathrm{~m}$ de comprimento, sendo considerado como área útil as quatro linhas centrais excluindo-se $1,0 \mathrm{~m}$ de bordadura de cada extremidade.

A colheita foi realizada manualmente no momento em que a cultura apresentou maturidade fisiológica. Para avaliação da produtividade as plantas foram trilhadas em uma trilhadora acoplada à tomada de potência do trator. Foram avaliados os teores de zinco foliares, onde foram coletados o terceiro trifólio, sem o pecíolo, a partir do ápice em 30 plantas na área útil de cada parcela no final do florescimento (estádio R3). O material foi seco em estufa de circulação forçada de ar $\left(65{ }^{\circ} \mathrm{C}\right)$ até atingirem peso constante. Após secas, as folhas foram moídas em moinho tipo Willey, para determinação dos teores totais de $\mathrm{Zn}$, conforme
Malavolta et al. (1997). As determinações do teor foliar de $\mathrm{Zn}$ foram realizadas no Laboratório de Fertilidade do Solo e Nutrição de Plantas do Instituto Federal Goiano, Campus Urutaí. Também foram avaliadas as seguintes características:

Teor relativo de clorofila - a leitura foi realizada em três folhas da área útil de cada parcela com o auxílio de um clorofilômetro portátil (ClorofiLOG modelo CFL 1030) quando as plantas estavam em estádio R3;

Altura de planta - quando as plantas estavam no estádio R8, com o auxílio de uma trena de escala graduada mediu-se a distância entre a superfície do solo e o ponto de inserção da última folha em seis plantas da área útil de cada parcela;

Diâmetro do caule - determinado com o auxílio do paquímetro digital quando as plantas encontravam-se em R8, medindo-se seis plantas da área útil de cada parcela;

Altura de inserção da primeira vagem - medindo-se com o auxílio de uma trena de escala graduada a distância entre a superfície do solo e o ponto de inserção da primeira vagem em seis plantas da área útil de cada parcela;

Número de vagens por planta e número de grãos por vagem - foram coletadas seis plantas da área útil de cada parcela quando as plantas encontravam-se em R8 e contou-se o número de vagens e grãos em cada vagem respectivamente;

Número de nós reprodutivos por planta - contou-se o número de nós com pelo menos uma vagem;

Massa de 100 grãos - determinada pela média de quatro amostras de 100 grãos de cada parcela. Os grãos foram contados manualmente e submetidos à pesagem $\mathrm{e}$ à determinação imediata da umidade, através de um medidor do conteúdo de água de grãos, portátil, Gehaka modelo G800. Após a determinação da umidade foi efetuada a correção do grau de umidade para $13 \%$;

Produtividade de grãos - manualmente, realizou a trilha e pesagem dos grãos oriundos de todas as plantas colhidas na área útil das parcelas experimentais. A produtividade de cada parcela foi convertida para $\mathrm{kg} \mathrm{ha}{ }^{-}$ ${ }^{1}$ e devidamente corrigida para $13 \%$ de umidade.

Os resultados foram submetidos à análise de variância e as médias comparadas pelo teste de Tukey a $5 \%$ de probabilidade. Para analisar as influências significativas das doses de $\mathrm{Zn}$ sobre as características avaliadas, trabalhou-se com análises de regressão. Foi utilizado o programa de análise estatística Sanest.

\section{Resultados e Discussão}

Os valores médios para o fator épocas de aplicação sobre as características diâmetro do caule, altura de planta, nós reprodutivos por planta, vagens por planta e teor relativo de clorofila encontram-se na Tabela 1 . 
Nenhuma destas características apresentou diferença significativa em relação às épocas de aplicação de Zn.

A altura de plantas teve influência significativa das doses de $\mathrm{Zn}$ apresentando efeito linear crescente com as maiores alturas sendo obtidas com as maiores doses de $\mathrm{Zn}$ (Figura 2A). As médias obtidas com as diferentes doses variaram de 57,58 a $63,4 \mathrm{~cm}$. Essa variação representa um aumento de $10,1 \%$ entre a menor e a maior dose de Zn. Resultados semelhantes foram encontrados por El Haggan (2014) e El Sayed et al. (2015), que verificaram um aumento 5,05 e 23,1\%, na altura de plantas de soja e canola, respectivamente, com aplicação foliar de $\mathrm{Zn}$.

O maior desenvolvimento das plantas de soja pode ser explicado devido à importância do micronutriente $\mathrm{Zn}$ para o crescimento das plantas atuando como ativador de várias enzimas, no metabolismo da auxina e associado ao metabolismo do nitrogênio. Assim, plantas bem nutridas com $\mathrm{Zn}$ apresentam divisão e alongamento celular mais rápido, aumentam a síntese de proteínas, tem maior desenvolvimento radicular, maior absorção de água e nutrientes e, consequente aumento do crescimento (SADEGHZADEH, 2013).

A variável diâmetro do caule teve influência significativa das doses de $\mathrm{Zn}$ apresentando efeito quadrático (Figura 2B). Conforme Carvalho et al. (2013) esta é uma variável muito importante, pois plantas com caules mais grossos suportam um maior número de galhos e vagens aumentando a produtividade. As médias obtidas com as diferentes doses variaram de 5,53 a 7,04 $\mathrm{mm}$, sendo que a menor média foi obtida na dose de $0 \mathrm{~kg} \mathrm{ha}^{-1}$ de $\mathrm{Zn}$ e a maior na dose de 9,88 $\mathrm{kg} \mathrm{ha}^{-1}$ de $\mathrm{Zn}$.

O número de nós reprodutivos por planta teve influência significativa das doses de $\mathrm{Zn}$ apresentando efeito linear crescente (Figura 2C), onde os valores foram de 19,86 a 24,92 nós reprodutivos por planta para as doses 0 e $12 \mathrm{~kg} \mathrm{ha}^{-1}$ de $\mathrm{Zn}$, respectivamente.

A deficiência hídrica causa forte redução no crescimento das plantas e na emissão de ramos reduzindo o número de nós que poderiam produzir vagens (MUNDSTOCK; THOMAS, 2005). Durante a condução do experimento ocorreu um déficit hídrico na cultura da soja no mês de janeiro, ficando 17 dias sem nenhuma precipitação, sendo que durante todo o mês a precipitação total foi de apenas $67,8 \mathrm{~mm}$ (Figura 1). Dessa forma, nos tratamentos com as menores doses de $\mathrm{Zn}$ ocorreu um menor desenvolvimento das plantas (Figura 2A) e, consequentemente, um menor número de nós reprodutivos (Figura 2C).

Para o número de vagens por planta ocorreu influência significativa das doses de $\mathrm{Zn}$ apresentando efeito linear crescente (Figura 2D). As médias obtidas com as diferentes doses variaram de 47,46 a 60,04 vagens por planta. Essa variação entre a dose de 0 a 12 $\mathrm{kg} \mathrm{ha}^{-1}$ de $\mathrm{Zn}$ representa aumento de 26,5\%. El Haggan (2014) e El Sayed et al. (2015) verificaram aumento de $13,48 \%$ e $38,42 \%$, respectivamente, no número de vagens por planta com a aplicação foliar de $\mathrm{Zn}$.

O número de vagens por planta é um componente de produção intimamente ligado ao número de nós reprodutivos por planta, desta forma plantas com maior número de nós reprodutivos, provavelmente, terão mais vagens, sendo que, o número de vagens por planta controla o número de grãos por planta e consequentemente, a produtividade. Dalchiavon e Carvalho (2012) verificaram que o número de vagens por planta foi o componente de produção que mais teve correlação com a produtividade da soja.

Para a variável índice relativo de clorofila (IRC) não houve efeito significativo entre as doses de $\mathrm{Zn}$ (Tabela 1). Os valores do IRC encontrados neste trabalho variaram de 40,98 a 41,12 para as adubações com $\mathrm{Zn}$ nos estádios V9 e R1, respectivamente.

Os valores médios para o fator épocas de aplicação sobre as características número de grãos por vagem, altura de inserção da primeira vagem, teor foliar de $\mathrm{Zn}$, massa de 100 grãos e produtividade de grãos encontram-se na Tabela 2. Para as variáveis número de grãos por vagem e altura de inserção da primeira vagem não houve diferença significativa em relação às épocas de aplicação de Zn.

Tabela 1. Valores médios de altura de planta (AP), diâmetro do caule (DC), número de nós reprodutivos por planta (NRP), número de vagens por planta (VP) e índice relativo de clorofila (IRC) em função das diferentes épocas de adubação com zinco na cultura da soja. Ipameri - GO, 2015

\begin{tabular}{|c|c|c|c|c|c|}
\hline Tratamento & $\begin{array}{l}\text { AP } \\
\text { (m) }\end{array}$ & $\begin{array}{c}\mathrm{DC} \\
(\mathrm{mm})\end{array}$ & NRP & VP & IRC \\
\hline \multicolumn{6}{|l|}{ Épocas } \\
\hline V9 & $60,34 \mathrm{a}$ & $6,45 \mathrm{a}$ & $22,78 \mathrm{a}$ & $55,51 \mathrm{a}$ & $40,98 \mathrm{a}$ \\
\hline $\mathrm{R} 1$ & $60,32 \mathrm{a}$ & $6,60 \mathrm{a}$ & $22,81 \mathrm{a}$ & $53,75 \mathrm{a}$ & $41,12 \mathrm{a}$ \\
\hline Test $\mathrm{F}$ & $0,279^{\mathrm{ns}}$ & $1,529^{\mathrm{ns}}$ & $0,001^{\mathrm{ns}}$ & $0,6179^{\mathrm{ns}}$ & $0,242^{\mathrm{ns}}$ \\
\hline Regressão & $\mathrm{L}$ & $\mathrm{Q}$ & $\mathrm{L}$ & $\mathrm{L}$ & -- \\
\hline Interação & $0,118^{\mathrm{ns}}$ & $1,591^{\mathrm{ns}}$ & $0,573^{\mathrm{ns}}$ & $0,641^{\mathrm{ns}}$ & $0,153^{\mathrm{ns}}$ \\
\hline CV (\%) & 6,14 & 5,66 & 13,29 & 12,95 & 2,11 \\
\hline
\end{tabular}

Médias na mesma coluna, seguidas por letras iguais, não diferem entre si pelo teste de Tukey a $5 \%$ de probabilidade (P $\leq 0,05)$. ${ }^{\text {ns }}$ : não significativo; $\mathrm{Q}$ : modelo quadrático; L: modelo linear. 

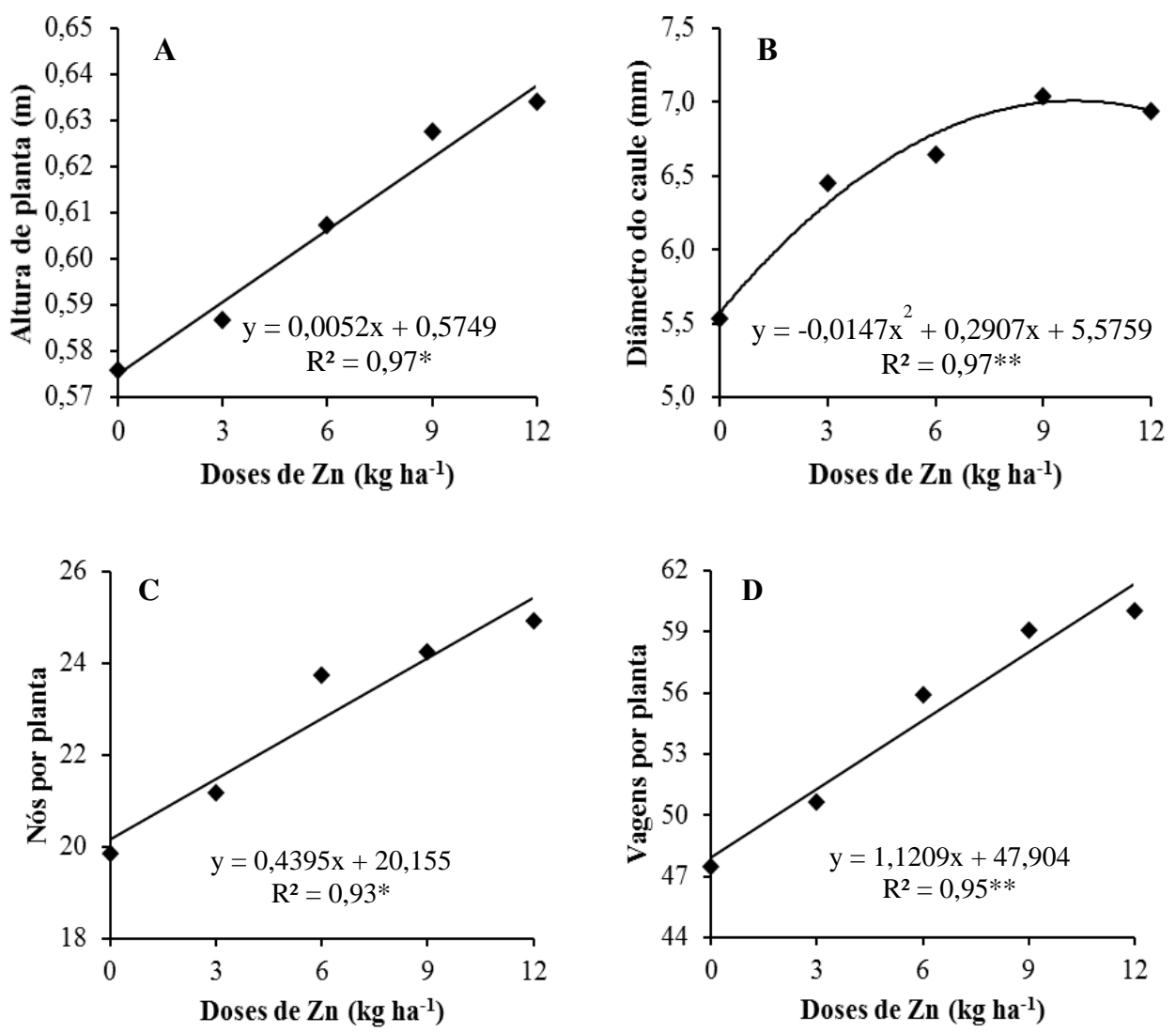

Figura 2. Altura de planta (A), diâmetro do caule (B), número de nós reprodutivos por planta (C) e número de vagens por planta (D) em função das doses de Zn aplicadas na cultura da soja. Ipameri - GO, 2015. ${ }^{* *}$ e ${ }^{*}$ : significativo a 1 e 5\% de probabilidade, respectivamente.

Para o número de grãos por vagem não ocorreu diferença significativa entre as doses de Zn (Tabela 2). Estes resultados divergem dos encontrados por Choudhary et al. (2014) que ao avaliarem a influência da adubação com enxofre (S) e Zn na soja verificaram um aumento no número de grãos por vagem quando se aplicou $10 \mathrm{~kg} \mathrm{ha}^{-1}$ de Zn. De acordo com Board e Kahlon (2011) quando ocorre estresse hídrico, como no presente trabalho, há uma redução no número de grãos por planta, porém essa redução está relacionada à uma redução no número de vagens por planta (Figura 2D) em vez de grãos por vagem.
Para o teor foliar de $\mathrm{Zn}$ houve diferença significativa tanto para as épocas, quanto para as doses de Zn. Em relação às épocas de aplicação de $\mathrm{Zn}$ o maior teor foliar de $\mathrm{Zn}$ foi encontrado em V9, o qual diferiu estatisticamente do valor de R1 (Tabela 3). Isto ocorreu devido a maior absorção de $\mathrm{Zn}$ quando este micronutriente foi aplicado no estádio V9. Para as doses o teor foliar de $\mathrm{Zn}$ apresentou comportamento linear positivo (Figura 3A). As médias obtidas com as diferentes doses variaram de 51,88 a 68,19 $\mathrm{mg} \mathrm{kg}^{-1}$ entre a menor e a maior dose. Raij et al. (1996) estabelecem que o teor de $\mathrm{Zn}$ foliar varia entre 20 a $50 \mathrm{mg} \mathrm{kg}^{-1}$.

Tabela 2. Valores médios do número de grãos por vagem (GV), teor foliar de zinco (TFZn), altura de inserção da primeira vagem (IPV), massa de 100 grãos (M100) e produtividade de grãos (PROD) em função das diferentes épocas de adubação com zinco na cultura da soja. Ipameri - GO, 2015

\begin{tabular}{|c|c|c|c|c|c|}
\hline \multirow{2}{*}{ Tratamento } & GV & TFZn & IPV & M100 & PROD \\
\hline & --- & $\left(\mathrm{mg} \mathrm{kg}^{-1}\right)$ & $(\mathrm{cm})$ & (g) & $\left(\mathrm{kg} \mathrm{ha}^{-1}\right)$ \\
\hline \multicolumn{6}{|l|}{ Épocas } \\
\hline V9 & $2,29 \mathrm{a}$ & $61,71 \mathrm{a}$ & $17,99 \mathrm{a}$ & $17,19 \mathrm{a}$ & $3.037 \mathrm{a}$ \\
\hline $\mathrm{R} 1$ & $2,26 \mathrm{a}$ & $57,69 \mathrm{~b}$ & $17,61 \mathrm{a}$ & $16,58 \mathrm{~b}$ & $2.826 \mathrm{~b}$ \\
\hline Test F & $1,121^{\mathrm{ns}}$ & $19,486^{* *}$ & $0,699^{\mathrm{ns}}$ & $7,156^{*}$ & $19,091^{* * *}$ \\
\hline Regressão & -- & $\mathrm{L}$ & $\mathrm{L}$ & $\mathrm{L}$ & $\mathrm{L}$ \\
\hline Interação & $1,875^{\mathrm{ns}}$ & $0.801^{\mathrm{ns}}$ & $0,398^{\mathrm{ns}}$ & $0,520^{\mathrm{ns}}$ & $0,539^{\mathrm{ns}}$ \\
\hline $\mathrm{CV}(\%)$ & 4,40 & 4,83 & 8,11 & 4,27 & 5,22 \\
\hline
\end{tabular}

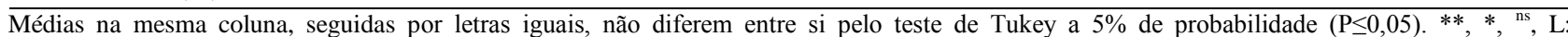
significativo a 1 e $5 \%$ de probabilidade, não significativo e modelo linear, respectivamente. 

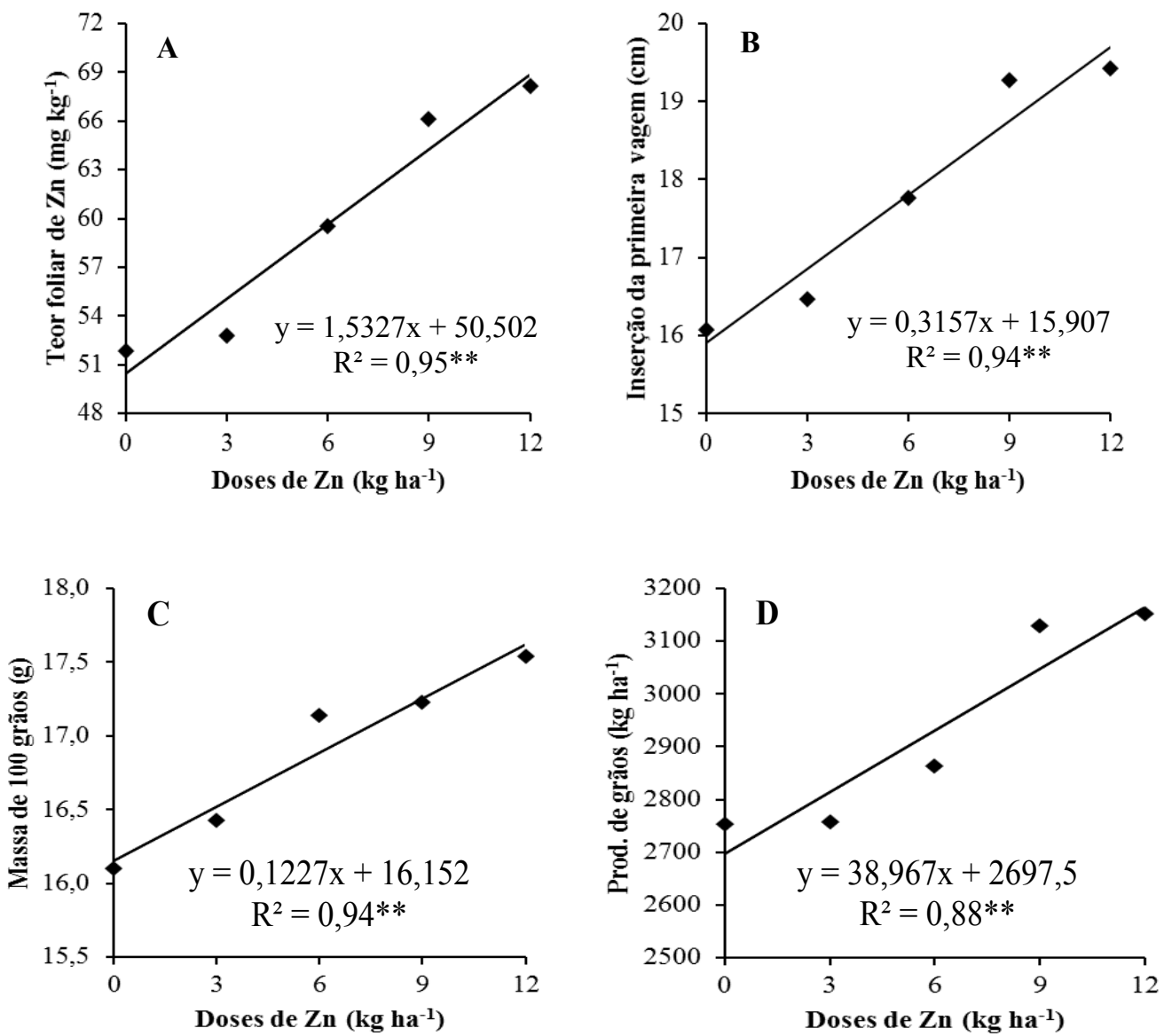

Figura 3. Teor foliar de zinco (A), altura de inserção da primeira vagem (B), massa de 100 grãos (C) e produtividade de grãos (D) em função das doses de Zn aplicadas na cultura da soja. Ipameri - GO, 2015. ${ }^{* *}$ : significativo a 1\% de probabilidade.

Neste trabalho não foram encontrados sintomas de deficiência de $\mathrm{Zn}$ em nenhum dos tratamentos, inclusive nas doses de $0 \mathrm{~kg} \mathrm{ha}^{-1}$ de $\mathrm{Zn}$. Esse fato concorda com os resultados encontrados na análise foliar de $\mathrm{Zn}$, onde todos os tratamentos se encaixaram na faixa de suficiência. Embora todos os teores foliares de $\mathrm{Zn}$ tenham sido suficientes, ocorreu uma maior absorção deste micronutriente onde foram aplicadas as maiores doses. Esses resultados se assemelham aos encontrados por De Muner et al. (2011) que verificaram aumento linear nos teores foliares de $\mathrm{Zn}$ na cultura do milho em relação às doses desse micronutriente aplicadas no solo, variando de 0 a $16 \mathrm{~kg} \mathrm{ha}^{-1}$ de $\mathrm{Zn}$. Embora tenha ocorrido aumento linear no teor foliar de $\mathrm{Zn}$, possivelmente grande parte da quantidade aplicada desse micronutriente não foi absorvida pelas plantas, pois em nenhuma das doses aplicadas foram encontrados teores considerados altos para o $\mathrm{Zn}$ no tecido foliar.

$\mathrm{Na}$ variável altura de inserção da primeira vagem houve influência significativa das doses de $\mathrm{Zn}$ apresentando efeito linear positivo (Figura 3B). As médias obtidas com as diferentes doses variaram de 16,08 a 19,42 cm entre a menor e a maior dose. A altura de inserção da primeira vagem está diretamente relacionada com a altura de plantas, sendo que essas características podem receber influência do ambiente e/ou práticas culturais e estão fortemente relacionadas com as cultivares de soja (LEMOS et al., 2011). Como pode ser observado neste trabalho, a altura de inserção da primeira vagem (Figura 3B) variou de acordo com a altura das plantas (Figura 2A), confirmando que essas características estão intimamente ligadas.

Para a massa de 100 grãos ocorreu diferença significativa tanto para as épocas de aplicação quanto para as doses de $\mathrm{Zn}$. Em relação às épocas de aplicação o maior teor foliar de $\mathrm{Zn}$ foi encontrado em V9, o qual diferiu estatisticamente do valor de R1 (Tabela 2). Para as doses a massa de 100 grãos apresentou comportamento linear crescente à medida que se aumentou as doses de $\mathrm{Zn}$ (Figura 3C). As médias obtidas com as diferentes doses variaram de 16,10 a 17,54 g entre a menor e a maior dose. Essa variação no peso representa um acréscimo de $8,9 \%$; resultado semelhante ao encontrado por El Haggan (2014) que verificaram um aumento de $11,9 \%$ na massa de 100 grãos com a aplicação foliar de Zn na soja.

A massa de grãos apresentou aumento, em relação às doses, semelhante ao valor encontrado para o teor foliar de $\mathrm{Zn}$. Essa relação se deve ao desempenho do $\mathrm{Zn}$ em importantes funções nas plantas como no metabolismo do $\mathrm{N}$ e dos carboidratos e na síntese de aminoácidos e proteínas (SADEGHZADEH, 2013). 
Os valores médios de produtividade em relação às épocas de aplicação de Zn estão na Tabela 2. Verifica-se que ocorreu diferença significativa entre as épocas, sendo que as aplicações em V9 apresentaram médias superiores às médias encontradas em R1. As maiores médias encontradas em V9 podem ser explicadas pelo fato de ter ocorrido uma maior absorção de Zn quando o micronutriente foi aplicado neste estádio, como pode ser verificado nos teores foliares de $\mathrm{Zn}$ (Figura 3A). Além disso, a massa de 100 grãos também apresentou maiores valores para V9 (Figura 3C) influenciando significativamente a produtividade.

Em relação às doses a produtividade apresentou acréscimo linear com a elevação das doses de $\mathrm{Zn}$ (Figura 3D). As médias obtidas com as diferentes doses variaram de 2.754 a $3.153 \mathrm{~kg} \mathrm{ha}^{-1}$, representando um acréscimo de $14,5 \%$ quando se aplicou $12 \mathrm{~kg} \mathrm{ha}^{-1}$ de $\mathrm{Zn}$, concordando com Keram et al. (2014) que encontraram um aumento de produtividade de 19,2\% quando se aplicou $10 \mathrm{~kg} \mathrm{ha}^{-1}$ de $\mathrm{Zn}$ na cultura do trigo.

Esse comportamento linear da produtividade foi semelhante ao comportamento apresentado pelo número de nós reprodutivos por planta, vagens por planta, e massa de 100 grãos, demonstrando que esses caracteres estão intimamente ligados com a produtividade sendo importante avaliá-los.

Cada trabalho pode apresentar uma determinada resposta ao uso do $\mathrm{Zn}$, dependendo da cultivar utilizada, das condições edafoclimáticas, do sistema de manejo, entre outros fatores. Inocêncio et al. (2012) obtiveram aumento da produtividade da soja utilizando adubação com $\mathrm{Zn}$ mesmo em solo com o teor elevado $\left(3,6 \mathrm{mg} \mathrm{dm}^{-}\right.$ ${ }^{3}$ ) desse micronutriente. Gonçalves Junior et al. (2010) não observaram interferência na produtividade e nos componentes de produção da cultura da soja quando aplicaram doses de zinco no solo.

Dessa forma, o Zn tem grande participação na planta por ser ativador de várias enzimas que estão envolvidas no metabolismo de carboidratos, regulador de auxinas e síntese e formação de polén, além de influenciar no crescimento, desenvolvimento e produção das plantas de soja.

\section{Conclusões}

A adubação com $\mathrm{Zn}$ influenciou positivamente o teor foliar de $\mathrm{Zn}$, altura de plantas, diâmetro do caule, altura de inserção da primeira vagem, número de vagens por planta, número de nós reprodutivos por planta, massa de 100 grãos e produtividade de grãos.

A massa de 100 grãos e a produtividade de grãos apresentaram diferença significativa entre as épocas de aplicação, com resultados superiores para as médias de V9. De acordo com estes resultados recomenda-se a adubação com $\mathrm{Zn}$ na cultura da soja

\section{Agradecimentos}

À Universidade Estadual de Goiás (UEG), Campus Ipameri, pelo suporte na condução do projeto e pela bolsa produtividade PROBIP ao terceiro autor. Ao CNPq pela bolsa de mestrado concedida ao primeiro autor.

\section{Referências Bibliográficas}

BAtAglia, O. C.; MASCARENHAS, H. A. A. Absorção de nutrientes pela soja. Campinas-SP: Instituto Agronômico, 1977. 36 p. (Boletim Técnico, 41).

BOARD, J. E.; KAHLON, C. S. Soybean yield formation: what controls it and how it can be improved. In: EL-SHEMY, H. A. Soybean physiology and biochemistry. In Tech Open Access Publish, Rijeka, Croatia, 2011. p. 1-36.

CARVALHO, J. C.; VIECELLI, C. A.; ALMEIDA, D. K. Produtividade e desenvolvimento da cultura da soja pelo uso de regulador vegetal. Acta Iguazu, Cascavel-PR, v. 2, n. 1, p. 50-60, 2013.

CHOUDHARY, P.; JHAJHARIA, A.; KUMAR, R. Influence of sulphur and zinc fertilization on yield, yield components and quality traits of soybean (Glycine Max L.). The Bioscan, Índia, v. 9, n. 1, p. 137-142, 2014.

DALCHIAVON, F. C.; CARVALHO, M. de P. e. Correlação linear e espacial dos componentes de produção e produtividade da soja. Semina: Ciências Agrárias, LondrinaPR, v. 33, n. 2, p. 541-552, 2012.

DE MUNER, L. H.; RUIZ, H. A.; VENEGAS, V. H. A.; NEVES, J. C. L.; FREIRE, F. J.; FREIRE, M. B. D. dos S. Disponibilidade de zinco para milho em resposta à localização de fósforo no solo. Revista Brasileira de Engenharia Agrícola e Ambiental, Campina Grande-PB, v. 15, n. 1, p.29-36, 2011.

EL HAGGAN, E. A. L. M. A. Effect of micronutrients foliar application on yield and quality traits of soybean cultivars. International Journal of Agriculture and Crop Sciences, Londres-Inglaterra, v. 7, n. 11, p. 908-914, 2014.

EL SAYED, S. A. A.; HELLAL, F. A.; MATTER, F. M. A.; MAHFOUZ, S. A. Micronutrient and compost induced changes of growth, yield, nutrient and phytochemical content of canola grown in saline soil. American-EurasianJournal of Sustainable Agriculture, Jordânia, Ma'an, v. 9, n. 3, p. 16-22, 2015.

EMBRAPA. EMPRESA BRASILEIRA DE PESQUISA AGROPECUÁRIA. Tecnologias de produção de soja Região Central do Brasil 2014. Londrina-PR: Embrapa Soja, 2013. 265 p. (Sistemas de Produção, 16).

FAQUIN, V. Nutrição Mineral de Plantas. Lavras-MG: Universidade Federal de Lavras/FAEPE, 2005. 186 p.

FREITAS, M. C. M. A Cultura da Soja no Brasil: O crescimento da produção brasileira e o surgimento de uma nova fronteira agrícola. Enciclopédia Biosfera - Centro Científico Conhecer, Goiânia-GO, v. 7, n. 12, p. 1-12, 2011. 
GARCIA, G. G.; SILVA, T. R. B.; SECCO, D. Épocas de aplicação e doses de fertilizante a base de cobre e zinco no rendimento de grãos de soja. Cultivando o Saber, CascavelPR, v. 2, n. 4, p. 18-25, 2009.

GONÇALVES JÚNIOR, A. C.; NACKE, H.; MARENGONI, N. G.; CARVALHO, E. A.; COELHO, G. F. Produtividade e componentes de produção da soja adubada com diferentes doses de fósforo, potássio e zinco. Ciência e Agrotecnologia, Lavras-MG, v. 34, n. 3, p. 660-666, 2010.

INMET. INSTITUTO NACIONAL DE METEOROLOGIA. Disponível http://www.inmet.gov.br/portal/index.php?r=bdmep/bdmep. Acesso em: 05 de janeiro de 2016.

INOCÊNCIO, M. F.; RESENDE, A. V.; NETO, A. E. F.; VELOSO, M. P.; FERRAZ, F. M.; HICKMANN, C. Resposta da soja à adubação com zinco em solo com teores acima do nível crítico. Pesquisa Agropecuária Brasileira, Brasília-DF, v. 47, n. 10, p. 1550-1554, 2012.

KERAM, K. S.; SHARMA, B. L.; KEWAT, M. L.; SHARMA, G. D. Effect of zinc fertilization on growth, yield and quality of wheat grown under agro-climatic condition of Kymore Plateau of Madhya Pradesh, Indía. The Bioscan, Jharkhand-Índia, v. 9, n. 4, p. 1479-1483, 2014.

LEMOS, N. G.; BRACCINI, A. L.; ABDELNOOR, R. V.; OLIVEIRA, M. C. N.; SUENAGA, K.; YAMANAKA, N. Characterization of genes Rpp2, Rpp4, and Rpp5 for resistance to soybean rust. Euphytica, Durham-CN, v. 182, n. 1, p. 53-64. 2011.

MALAVOLTA, E.; VITTI, C. G.; OLIVEIRA, S. A. Avaliação do estudo nutricional das plantas: princípios e aplicações. Piracicaba-SP: Potafós, 1997. 319 p.

MALAVOLTA, E.; KLIEMANN, H. J. Desordens nutricionais no cerrado. Piracicaba-SP: Potafós, 1985. 136 p.

MARSCHNER, P. Marschner's mineral nutrition of hight plants. 3. ed. Oxford-Inglaterra: Elsevier, 2012. 643 p.

MUNDSTOCK, C.M.; THOMAS, A. L. Soja: fatores que afetam o crescimento e o rendimento de grãos. Porto AlegreRS: Evangraf, 2005. 31 p.
RAIJ, B. V.; CANTARELLA, H.; QUAGGIO, J. A.; FURLANI, A. M. C. Recomendações de adubação e calagem para o Estado de São Paulo. 2. ed. Campinas-SP: IAC, 1996. 285 p. (Boletim técnico, 100).

RESENDE, A. V. Adubação da soja em areas do cerrado: micronutrientes. Planaltina-GO: Embrapa Cerrados, 2004. 29p. (Documentos, n. 115).

RIBEIRO, A. C.; GUIMARÃES, P. T. G.; ALVAREZ, V. H. Recomendações para o uso de corretivos e fertilizantes em Minas Gerais $-5^{\text {a }}$ aproximação. Viçosa-MG: UFV, 1999. 359 p.

SADEGHZADEH, B. A review of zinc nutrition and plant breeding. Jornal of Soil Science and Plant Nutrition, Temuco-Chile, v. 13, p. 905-927, 2013.

SANTOS H. G.; JACOMINE P. K. T.; ANJOS L. H. C.; OLIVEIRA V. A.; LUMBRERAS J. F.; COELHO M. R.; ALMEIDA J. A.; CUNHA T. J. F.; OLIVEIRA J. B. Sistema brasileiro de classificação de solos. 3.ed. Brasília-DF: Embrapa, 2013. 353p.

SFREDO, G. J. Soja no Brasil: calagem, adubação e nutrição mineral. Londrina-PR: Embrapa Soja, 2008. 148 p. (Documentos n. 305).

SOUZA, L. H.; NOVAIS, R. F.; ALVAREZ, V. V. H.; VILLANI, E. M A. Efeito do $\mathrm{pH}$ do solo rizosférico e não rizosférico de plantas de soja inoculadas com Bradyrhizobium japonicum na absorção de boro, cobre, ferro, manganês e zinco. Revista Brasileira de Ciência do Solo, Viçosa-MG, v. 34, n. 5, p. 1641-1652. 2010.

VENDRAME, P. R. S.; BRITO, O. R.; QUANTIN, C.; BECQUER, T. Disponibilidade de cobre, ferro, manganês e zinco em solos sob pastagens da Região do Cerrado. Pesquisa Agropecuária Brasileira, Brasília-DF, v. 42, n. 6, p. 859-864, 2007

ZONTA, E. P.; MACHADO, A. A. SANEST - Sistema de análise estatística para microcomputadores. Pelotas-RS: DMEC/IFM/UFPel, 1987. 138 p. 